\title{
Homozygous Deletion Mutation of the FERMT1 Gene in a Chinese Patient with Kindler Syndrome
}

\author{
Seung Joon Oh, Song-Ee Kim, Sang Eun Lee, Soo-Chan Kim \\ Department of Dermatology and Cutaneous Biology Research Institute, Gangnam Severance Hospital, Yonsei University College of \\ Medicine, Seoul, Korea
}

\begin{abstract}
Dear Editor:
Kindler syndrome (KS, OMIM173650) is a rare autosomal recessive genodermatosis characterized by trauma-induced skin blistering, cutaneous atrophy, progressive poikiloderma and photosensitivity ${ }^{1}$. KS is caused by mutation in the FERMT1 gene ${ }^{1}$. This gene encodes kindlin-1, which regulates not only keratinocyte adhesion through $\beta_{1}$-class integrins but also proliferation and differentiation of cutaneous stem cells by promoting $\alpha_{v} \beta_{6}$ integrin-mediated transforming growth factor- $\beta$ activation and inhibiting Wnt ligand expression ${ }^{2}$.

A 12-year-old Chinese boy presented with recurrent blistering after mild trauma from the age of 1 year. There is no family history. Physical examination revealed generalized skin atrophy with some scattered resolving blisters on the extremities and poikiloderma on the face and neck (Fig. 1). He has also suffered from pruritus and photosensitivity. A skin biopsy from non-blistered area on his leg revealed hyperkeratosis and epidermal atrophy (Fig. 2A). Immunofluorescence (IF) mapping of a blister showed that keratins 5 and 14 were localized at the roof of the blister while laminin 5 and type IV collagen were localized at the base (Fig. 2B, C). Electron microscopic findings of non-blistered skin revealed widening of the lamina lucida and reduplication of the lamina densa (Fig. 2D). DNA extracted from
\end{abstract}

Received May 8, 2015, Revised July 25, 2015, Accepted for publication July 27,2015

Corresponding author: Soo-Chan Kim, Department of Dermatology, Gangnam Severance Hospital, Yonsei University College of Medicine, 211 Eonju-ro, Gangnam-gu, Seoul 06273, Korea. Tel: 82-2-2019-3362, Fax: 82-2-3463-6136, E-mail: kimsc@yuhs.ac

This is an Open Access article distributed under the terms of the Creative Commons Attribution Non-Commercial License (http://creativecommons. org/licenses/by-nc/4.0) which permits unrestricted non-commercial use, distribution, and reproduction in any medium, provided the original work is properly cited.

Copyright (c) The Korean Dermatological Association and The Korean Society for Investigative Dermatology the patient's blood was processed for direct nucleotide sequencing and we detected a homozygous dinucleotide deletion mutation at c.994_995delCA in exon 8. The mutation causes frameshift and a premature stop codon (Fig. $2 \mathrm{E})$. Based on these results, we diagnosed the patient with $\mathrm{KS}$.

KS usually manifests at birth with trauma-induced skin blistering that is more prominent on the extremities and
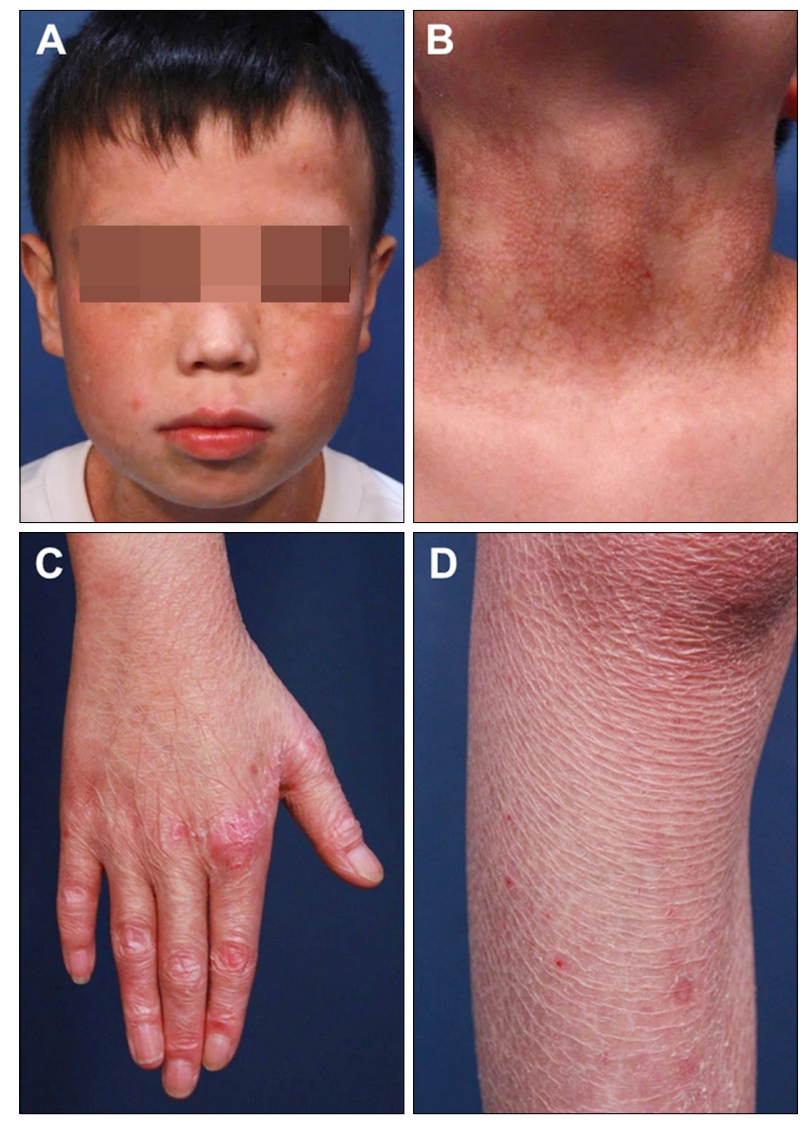

Fig. 1. Clinical features of the patient. (A, B) Poikiloderma on the face and neck. (C) Atrophic change on the dorsal aspect of hand. (D) Skin atrophy with resolving blisters on the leg. 

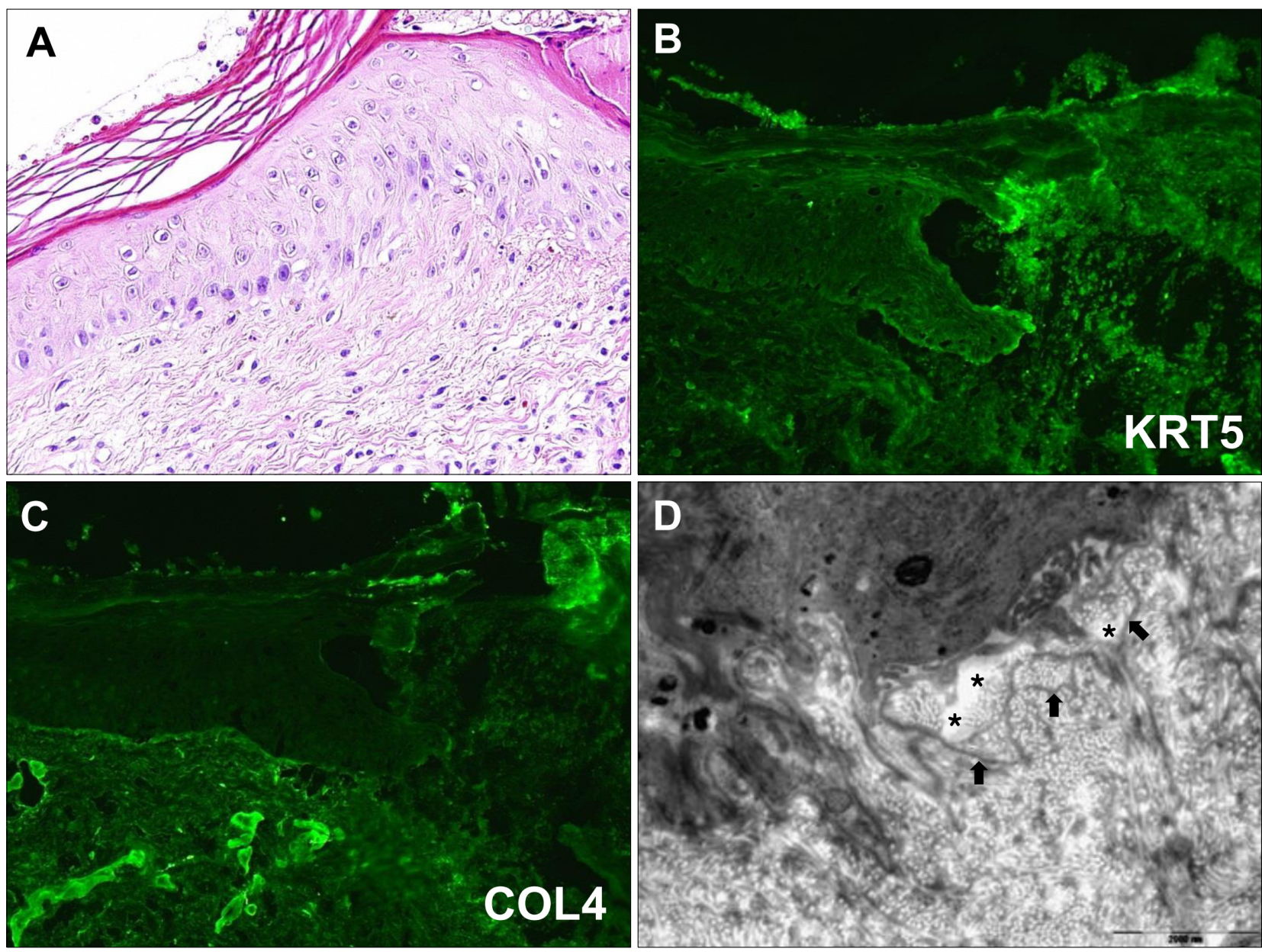

$\mathbf{E}$

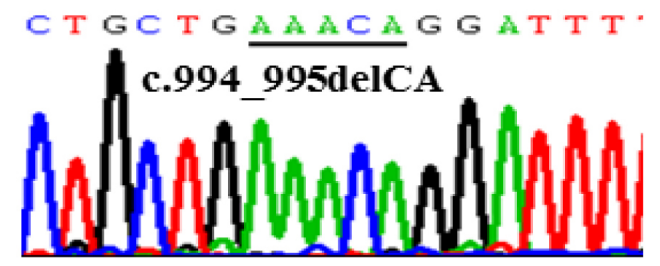

Fig. 2. (A) Histological examination. Hyperkeratosis and epidermal atrophy $(\mathrm{H} \& \mathrm{E}, \times 400)$. (B, C) Immunofluorescence mapping shows separation between keratin 5 (KRT5) and type IV collagen (COL4). KRT5 is localized at the roof of the blister (B) while COL4 is localized at the base (C). (D) Electron microscopic features. Stretches of lamina lucida (asterisks) and reduplication of lamina densa (arrows) (bar $=2,000 \mathrm{~nm}$ ). (E) Genetic analysis of the FERMT1 gene shows homozygous mutation at c.994_995delCA.

tends to regress with age ${ }^{3}$. However, as patients age, skin atrophy localized to the dorsal aspects of the hands and feet become generalized and progressive skin poikiloderma manifests. Most patients also show photosensitivity $^{3}$. Although our patient had no history of mucosal lesions, mucosal involvement is common'.

Histopathology and IF mapping of a blister are not informative for diagnosis because the plane of cleavage can be variable at the level of the basement membrane zone". Transmission electron microscopy of the non-blistered skin shows extensive reduplication of the lamina densa which is a characteristic diagnostic feature of $\mathrm{KS}^{4}$. The diagnostic golden standard is sequencing of the FERMT1 gene'.

To date, more than 60 FERMT1 gene mutations and 150 KS patients have been reported and one Chinese and 4 Japanese patients have been reported in Eastern $\mathrm{Asia}^{5}$ (https://grenada.lumc.nl/LOVD2/mendelian_genes/home.p $h p$ ? select_db =FERMT1). Most mutations cause premature termination of translation, therefore loss of kindlin-1 function and most patients are related with consanguineous marriages $^{3}$. Recently, Youssefian et al. ${ }^{4}$ first reported the 
c.994_995delCA mutation in a 19-year-old Iranian female patient. Interestingly, that patient had no mucosal involvement except dental plaques. This may imply an association between the mutation and mucosal-sparing features. Has et al. ${ }^{3}$ suggested genotype-phenotype correlations in $\mathrm{KS}$ because some patients with a missense mutation or in-frame deletion demonstrate a mild phenotype. However, only two cases including ours have been reported to date and our patient might be too young to have developed mucosal lesions. Further studies are needed to clarify this association.

\section{REFERENCES}

1. Lai-Cheong JE, Tanaka A, Hawche G, Emanuel P, Maari C, Taskesen $M$, et al. Kindler syndrome: a focal adhesion genodermatosis. Br J Dermatol 2009;160:233-242.

2. Rognoni E, Widmaier M, Jakobson M, Ruppert R, Ussar S, Katsougkri D, et al. Kindlin-1 controls Wnt and TGF- $\beta$ availability to regulate cutaneous stem cell proliferation. Nat Med 2014;20:350-359.

3. Has C, Castiglia D, del Rio M, Diez MG, Piccinni E, Kiritsi $\mathrm{D}$, et al. Kindler syndrome: extension of FERMT1 mutational spectrum and natural history. Hum Mutat 2011;32:12041212.

4. Youssefian L, Vahidnezhad H, Barzegar M, Li Q, Sotoudeh S, Yazdanfar A, et al. The Kindler syndrome: a spectrum of FERMT1 mutations in Iranian families. J Invest Dermatol 2015; 135:1447-1450.

5. Ohashi A, Kiniwa Y, Okuyama R, Kosho T, Suga T, Has C, et al. A case of Kindler syndrome with severe esophageal stenosis. Int J Dermatol 2015;54:e106-e108.

\title{
A Case of Facial Sarcoptes scabiei in a Female Child
}

\author{
Joon Seok, Kui Young Park, Kapsok Li, Beom Joon Kim, Seong Jun Seo, Myeung Nam Kim, \\ Chang Kwun Hong
}

Department of Dermatology, Chung-Ang University College of Medicine, Seoul, Korea

\section{Dear Editor:}

Scabies in infants and young children differs from adult scabies infection and is frequently misdiagnosed ${ }^{1}$.

An 8-year-old female presented with erythematous scaly pustules on her cheeks that start 3 months prior and had spread to her forehead. She was diagnosed at a local clinic with folliculitis, at which time she was treated with anti-

Received May 18, 2015, Revised June 8, 2015, Accepted for publication July 27, 2015

Corresponding author: Kui Young Park, Department of Dermatology, Chung-Ang University Hospital, 102 Heukseok-ro, Dongjak-gu, Seoul 06973, Korea. Tel: 82-2-6299-1525, Fax: 82-2-823-1049, E-mail: kyky@medimail.co.kr

This is an Open Access article distributed under the terms of the Creative Commons Attribution Non-Commercial License (http://creativecommons. org/licenses/by-nc/4.0) which permits unrestricted non-commercial use, distribution, and reproduction in any medium, provided the original work is properly cited.

Copyright $\odot$ The Korean Dermatological Association and The Korean Society for Investigative Dermatology

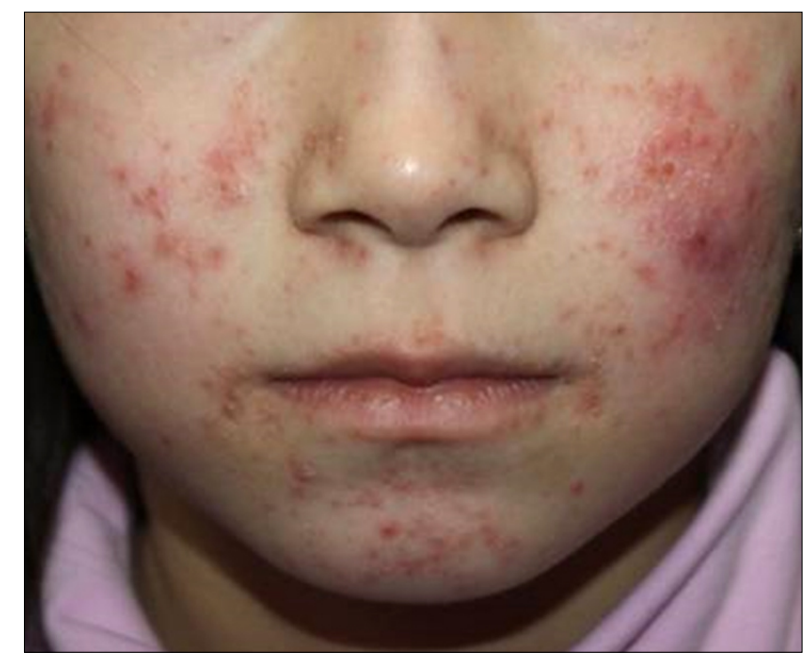

Fig. 1. Scattered, $2 \sim 3 \mathrm{~mm}$ sized, erythematous scaly pustules and a firm nodule on the face. 